\title{
Immune regulation in T1D and T2D: prospective role of Foxp3+Treg cells in disease pathogenesis and treatment
}

\author{
Mara Kornete $^{1,2 \dagger}$, Edward S. Mason ${ }^{1,2 \dagger}$ and Ciriaco A. Piccirillo ${ }^{1,2 *}$ \\ ${ }^{1}$ Department of Microbiology and Immunology, McGill University, Montreal, OC, Canada \\ ${ }^{2} \mathrm{FOCIS}$ Center of Excellence, Research Institute of the McGill University Health Center, Montreal, OC, Canada
}

\section{Edited by:}

Gabriel Virella, Universidade de Lisboa, Portugal

Reviewed by:

Undurti Narasimha Das, UND Life Sciences, USA

Eesh Bhatia, Sanjay Gandhi

Postgraduate Institute of Medical

Sciences, India

*Correspondence:

Ciriaco A. Piccirillo, Research Institute of the McGill University Health

Center, Montreal General Hospital, 1650 Cedar Avenue, Room L11.132,

Montreal, OC H3G 1A4, Canada

e-mail: ciro.piccirillo@mcgill.ca

${ }^{\dagger}$ Mara Kornete and Edward S. Mason

have contributed equally to this work.
There is increasing evidence that dysregulated immune responses play key roles in the pathogenesis and complications of type 1 but also type 2 diabetes. Indeed, chronic inflammation and autoimmunity, which are salient features of type 1 diabetes, are now believed to actively contribute to the pathogenesis of type 2 diabetes. The accumulation of activated innate and adaptive immune cells in various metabolic tissues results in the release of inflammatory mediators, which promote insulin resistance and $\beta$-cell damage. Moreover, these dysregulated immune responses can also mutually influence the prevalence of both type 1 and 2 diabetes. In this review article, we discuss the central role of immune responses in the patho-physiology and complications of type 1 and 2 diabetes, and provide evidence that regulation of these responses, particularly through the action of regulatory T cells, may be a possible therapeutic avenue for the treatment of these disease and their respective complications.

Keywords: inflammation, obesity, Foxp3, Treg, diabetes, metabolic, immune regulation

\section{THE PATHOGENESIS OF TYPE 1 DIABETES}

Type 1 diabetes (T1D) is a chronic autoimmune disease resulting from a $\mathrm{T}$ cell-dependent (both $\mathrm{CD} 4^{+}$and $\mathrm{CD} 8^{+}$) destruction of the insulin-producing $\beta$-islets of Langerhans in the pancreas, leading to insulin deficiency and persistent hyperglycemia (Figure 1). Upon $\beta$-cells destruction, T1D patients lose blood glucose control, which provoke severe hyperglycemia. Even with current insulin replacement therapies secondary complications such as heart disease, blindness, and kidney failure may arise. Diagnosis is typically made early in life, with onset as young as 1 year of age and in most cases before the age of 18 . The appearance of diabetes associated autoantibodies in the serum is the first detectable sign of emerging $\beta$-cell autoimmunity with over $90 \%$ of T1D patients testing positive for at least one at the time of diagnosis. Notable T1D auto-antigens identified include insulin, GAD65 (glutamic acid decarboxylase, $65 \mathrm{kDa}$ isoform), IA2 (insulin auto-antigen 2), and zinc transporter 8 (ZNT8) (Sabbah et al., 1999; Orban et al., 2009). Several reports suggest that insulin is a primary auto-antigen for disease initiation. For example, elimination of pro-insulin or insulin completely abolished insulitis and T1D in NOD mice, while removal of another islet antigen, IGRP, did not show protective effect (Krishnamurthy et al., 2006). Both, genetic and poorly defined environmental factors act together to precipitate disease progression. Most studies confirm a global increase in incidence of T1D, particularly among young children. This likely reflects various environmental changes, although the impact of any individual exogenous factor has not yet been definitively proven. Pathogens such as viruses and bacteria, early exposure to cow's milk, gluten, and meat preservatives and deficiency in dietary Vitamin D or omega 3 fatty acids have been proposed to contribute to the pathogenesis of T1D (Knip et al., 2005). Many epidemiological efforts have been made to understand the potential role of viruses in T1D pathogenesis. It is possible that viral antigenic mimicry could result in cross-reactive responses toward islet antigens. The striking sequence similarities between the $2 \mathrm{C}$ protein from coxsackievirus and GAD, a major auto-antigen in T1D, support this notion (Kaufman et al., 1992). Alternatively induction of a pro-inflammatory anti-viral response to infection, could activate innate immune cells, break tolerance, and initiate autoimmunity. It has also been established that in response to the viral infection, endocrine islet cells are able to produce pro-inflammatory cytokines, such as IL-8, IL-6, TNF $\alpha$, and CXCL10 that could further trigger abnormal immune responses and T1D (Christen et al., 2003; Berg et al., 2006). The gut microbiota, via interaction with the host innate immune system, has been shown to modulate T1D onset (Chervonsky, 2010). For example, in NOD mice, T1D incidence dramatically decreases when mice are exposed to various microbial products. Similarly, the so called "hygiene hypothesis" suggests that the marked increase in T1D incidence in industrialized countries is related to reduced helminth burden therein (Mathis and Benoist, 2012).

Early studies indicate that multiple genes within human leukocyte antigen (HLA) on chromosome 6 are critical susceptibility loci for human autoimmune disease, including T1D. Two T1D associated haplotypes, namely DR4-DQ8 and DR3-DQ2, are present in $90 \%$ of children with the disease. Candidate gene studies identify insulin as a second important gene associated with T1D susceptibility, contributing $10 \%$ of genetic susceptibility to T1D. Over the last decade, whole genome screens have identified at least 40 other loci associated with T1D. Furthermore, 


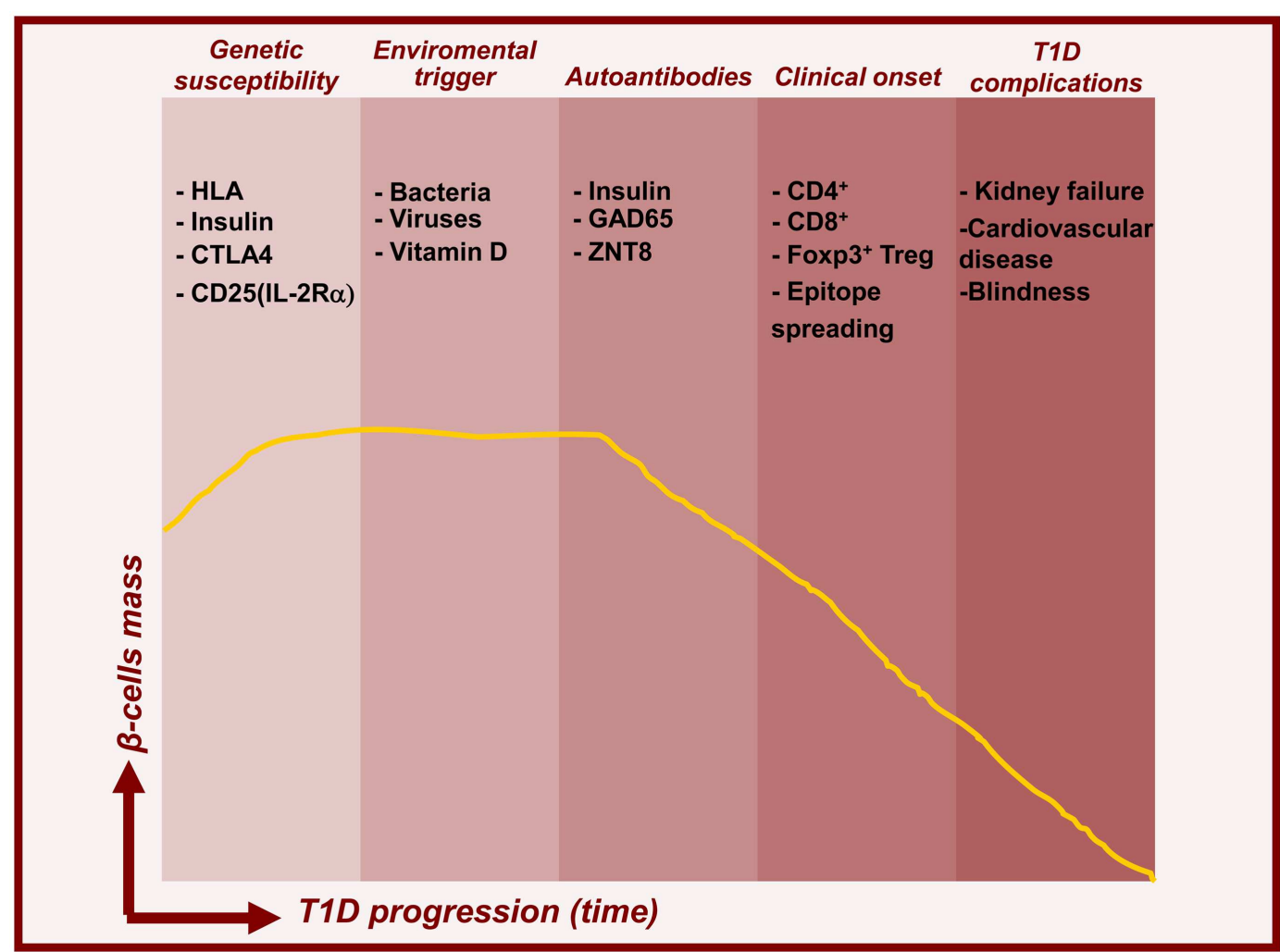

FIGURE 1 |Timelines for type 1 diabetes. Model for temporal relationship between beta-cell mass decline and features of T1D pathogenesis. In addition to genetic predisposition, environmental triggers induce islet autoimmunity and beta-cell death leading to prediabetes and subsequent clinical onset and complications.

mutations in genes found in several of the susceptibility loci, such as il-2, il-2ra, Ctla-4, PTPN22, il-10 have various autoimmune manifestations, including T1D. These genes are associated with the regulation of immune responses either by intrinsically controlling $\mathrm{T}$ and $\mathrm{B}$ cell reactivity or by enhancing the development and homeostasis of immunosuppression mediated by regulatory $\mathrm{T}$ (Treg) cells expressing Foxp3, a DNA-binding forkhead winged helix transcriptional regulator known to drive their lineage development.

Genetic susceptibility in humans and mice are both linked to variations in the IL-2 signaling pathway. In humans, T1D risk is related to the gene region encoding IL-2R $\alpha$, whereas in NOD mice the IL-2 gene (Idd3 locus) confers susceptibility (Lyons et al., 2000). Additionally, it has been established that phosphorylation of STAT5, a crucial IL-2 signaling molecule, is reduced in T1D patients, and could account for diminished Treg cell numbers (Long et al., 2010). Furthermore, proper IL-2 signaling is essential for protection from diabetes in NOD mice. Work from our group and others has demonstrated that protective IL-2 allelic variants favor the expansion and suppressive function of Treg cells directly in the islets (Sgouroudis et al., 2008). Moreover, treatment of diabetic mice with IL-2 increases Treg cell numbers and induces expression of Treg cell-associated proteins such as Foxp3, CD25, ICOS, and CTLA-4. Collectively IL-2 preferentially enhances Treg immunosuppression and down-regulates
IFNy production by pathogenic, islet-infiltrating effector T cells (Teff) (Grinberg-Bleyer et al., 2010).

\section{FOXP3+ TREG CELLS - MASTER REGULATORS OF THE IMMUNE SYSTEM}

Natural CD4 ${ }^{+}$Treg cells which express Foxp3 and develop in the thymus, represent a unique lineage of $\mathrm{T}$ cells with the ability to suppress autoimmune and pathological responses (Figure 2, top panel) (Piccirillo et al., 2005). They represent $1-10 \%$ of thymic and peripheral circulating $\mathrm{CD} 4^{+} \mathrm{T}$ cells in mouse and human, and are able to down-regulate the activation and function of various immune effector cell subsets. Alternatively, Treg cells can differentiate in the periphery from conventional $\mathrm{T}$ cells upon reception of antigen-specific stimulation along with tolerogenic cytokine signals. Natural and induced Treg cells are characterized by the constitutive expression of the IL-2R $\alpha$ chain (CD25) and preferentially express Foxp3 (Fontenot et al., 2005). The importance of Foxp 3 has been demonstrated by mutations in the foxp 3 gene that result in the loss of Treg cell function and the development of multi-organ autoimmunity, including autoimmune diabetes, in IPEX patients and Scurfy mice (Hori et al., 2003; d'Hennezel et al., 2012). Several factors like IL-2 and TGF $\beta$ have been identified that can enhance stabilize Foxp3 expression via demethylation of CpG motifs within conserved regions of Foxp3 promoter (Shen et al., 2009; Haiqi et al., 2011). Treg cell mediated suppression 


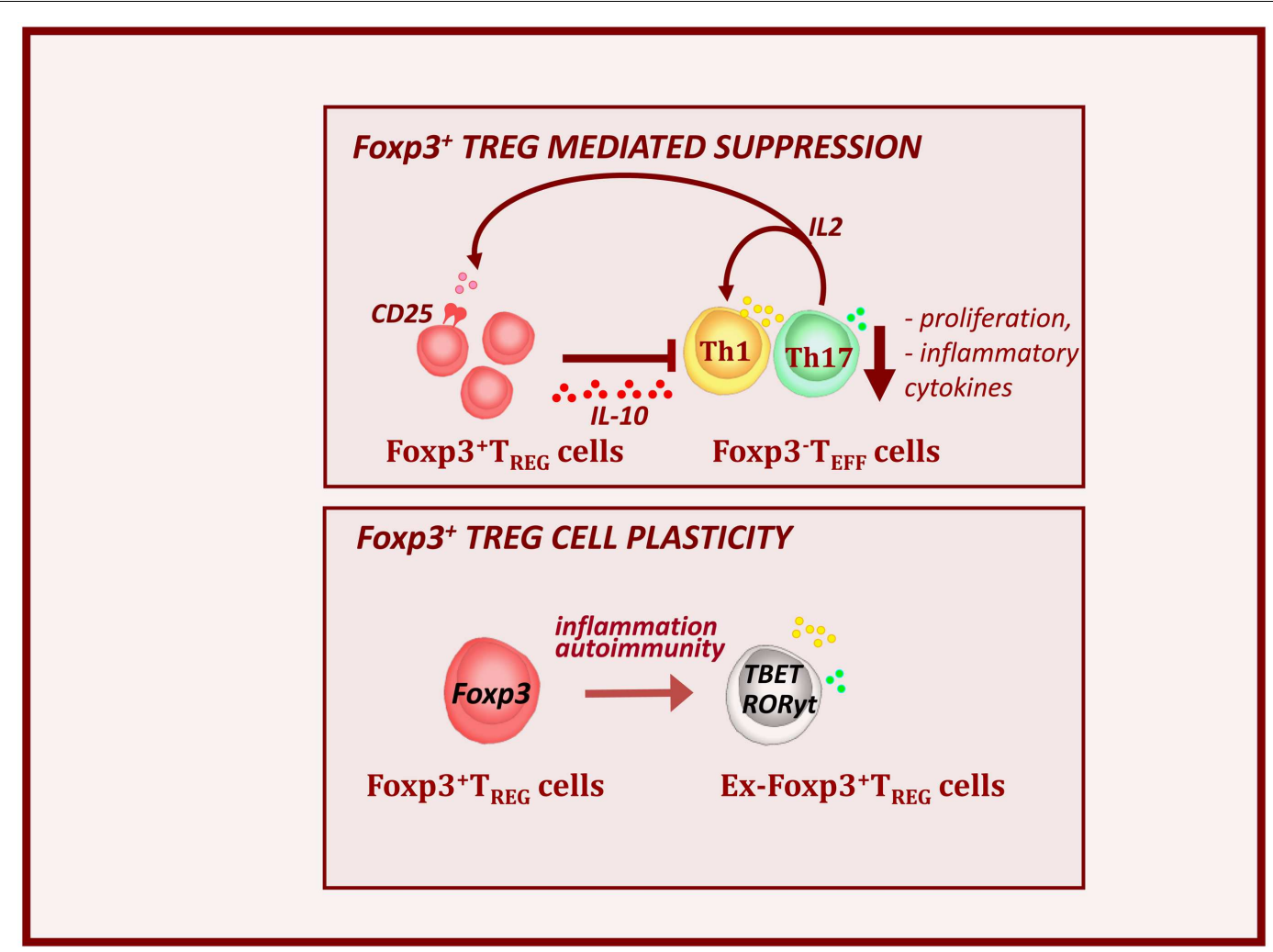

FIGURE 2 | Foxp3+ Treg cells control autoimmunity andT1D pathogenesis. Foxp3+ Treg cells express high levels of IL-2Ra or CD25 and are dependent on Teff-derived IL-2. Alterations in local IL-2 production may precipitate T1D by perturbing Treg cell function. Treg cells produce the immunosuppressive cytokine IL-10. This results to the down-regulation of inflammatory cytokines (IFNy and IL-17) and decreased expansion of effector cell pools. However during the T1D progression, inflammatory signals, can provoke loss of Foxp3 expression. These, so called ex-Foxp3 Treg cells acquire an effector cell phenotype in terms of transcription factor expression and inflammatory cytokine production and contribute to T1D pathology. As widely observed features of Treg cell biology in autoimmune. mechanisms are numerous and complex, including several cell surface and soluble factors that directly control activation of effector cells. Suppression is likely mediated via cell-cell contact dependent mechanisms and production of immunomodulatory cytokines such as IL-10 and TGF- $\beta$, IL-35, that inhibit DC and T cell activity (Sakaguchi et al., 2009; Shevach, 2009).

\section{THE IMMUNE-PROTECTIVE ROLE OF TREG CELLS IN T1D}

The critical importance of Treg cells in autoimmune settings, such as T1D, is well established (Atkinson and Leiter, 1999; Bach and Chatenoud, 2001). In NOD mice, depletion of CD4+CD25+ Treg cells accelerates development of T1D (Salomon et al., 2000; Salomon and Bluestone, 2001). Furthermore, abolishment of costimulatory pathways that are vital for Treg homeostasis, such as CD28 and ICOS, in NOD mice exacerbates T1D (Salomon and Bluestone, 2001; Anderson and Bluestone, 2005; Kornete et al., 2012).

We and others have shown that T1D progression is NOD mice is associated with a decrease in numbers and function of Treg cells in the inflamed islets and defects in IL-2 production by effector T cells seem largely responsible (Sgouroudis et al., 2008; Tang et al., 2008; Tritt et al., 2008; Kornete et al., 2012). Overall, this demonstrates that Treg cells function as major controllers of immune homeostasis and tolerance in the periphery. However, more recent finding indicated that Treg cells can become unstable and lose Foxp3 expression in inflamed pancreatic sites during T1D progression (Figure 2, bottom panel) (Zhou et al., 2009; McClymont et al., 2011). In the NOD mice, the lack of intra-islet IL-2 results in CD25 down-regulation and consequent reduction in Foxp3 expression. These ex-Foxp3 $+\mathrm{T}$ cells produce inflammatory cytokines, such as IFNy and IL-17 and have increased immunopathogenic potential upon adoptive transfer (Zhou et al., 2009). A similar observation has been made in T1D patients, in which a significant increase in the number of IFN $\gamma$ and IL-17 secreting Foxp3+ Treg cells was observed (McClymont et al., 2011).

\section{BETA ( $\beta$ ) CELLS: REGENERATION AND TRANS-DIFFERENTIATION}

The presence of $\beta$-cells in patients with long lasting T1D, despite ongoing autoimmunity, suggests that regeneration of $\beta$-cells may occur. About $60 \%$ of T1D patients enter a clinical "honeymoon phase," lasting between 3 months and 2 years, and characterized by improved insulin secretion to the extent that some patients can discontinue exogenous insulin (Muhammad et al., 1999; AbdulRasoul et al., 2006). $\beta$-cells have a robust capacity to regenerate by proliferation, likely in response to inflammation-driven signals 
(Akirav et al., 2008). Furthermore, recent studies revealed a previously unrecognized plasticity of endocrine cells in the pancreas. However, depending on the nature of experimental $\beta$-cell destruction, these studies reached divergent conclusions regarding the origin of new $\beta$-cells. Supporting the hypothesis of self-renewal, partial abolition results in $\beta$-cell regeneration from surviving $\beta$ cells (Dor et al., 2004; Nir et al., 2007). However, when more >99\% of $\beta$-cells are chemically destroyed, new $\beta$-cells are generated either via differentiation of endocrine and islet precursors (Guz et al., 2001; Thyssen et al., 2006) or by spontaneous reprograming of differentiated endocrine cell types such as $\delta$-cells (Fernandes et al., 1997) or $\alpha$-cells (Chung et al., 2010; Thorel et al., 2010; Zaret and White, 2010).

Several factors have been proposed to influence $\beta$-cells regeneration. Inflammation, though driving autoimmune responses, is implicated in $\beta$-cells proliferation. For example, while Th1 cellderived IFN- $\gamma$ is the main mediator of diabetogenesis in the NOD mice, the transgenic expression of IFN- $\gamma$ enhances $\beta$-cells proliferation and survival (Tuch et al., 1991; Ablamunits et al., 2007). Similarly, inflammatory cytokines such as IL-1 $\beta$, nitric oxide (NO), and TNF- $\alpha$ were shown to cause $\beta$-cell replication (Donath et al., 2003; Luo et al., 2005). More recently, Herold's group demonstrated that increased $\beta$-cell proliferation depends on the inflammatory infiltrate itself and immunotherapeutic regimens, namely administration of anti-CD3 mAb and Foxp $3^{+}$ Treg cells that suppress inflammatory T cells, also decrease $\beta$-cell replication (Sherry et al., 2006).

\section{THE CONTROL OF T1D COMPLICATIONS BY TREG CELLS: THE CASE FOR ATHEROSCLEROSIS}

Persistent, dysregulated inflammation contributes to the development of secondary chronic disorders such as vascular or neurodegenerative disease in T1D patients. One of the most common T1D complications is atherosclerosis, an inflammatory disorder of the arterial wall caused by the retention of cholesterol in the subendothelial region of the artery. Whereas inflammation is driven by both innate and adaptive immune effector cells, recent studies suggest that Foxp3+ Treg cells control the development and progression of atherosclerosis (Veillard et al., 2004; de Boer et al., 2007). Treg cells account for $1-5 \%$ of $\mathrm{T}$ cell population within atherosclerotic lesions in which they produce of immunomodulatory cytokines, such as IL-10 and TGF- $\beta$ (de Boer et al., 2007). Pro-atherogenic ApoE-deficient mice exhibit significantly lower numbers of Treg cells than their wild type counterparts (Mallat et al., 2003). The role of Treg cells was further elucidated via generation of low density lipoprotein receptor knock-out chimeric mice (Ait-Oufella et al., 2006). Reconstitution of these mice following irradiation with CD80/CD86 and CD28 deficient bone marrow cells resulted in a marked reduction in Treg cells and an increase in atherosclerotic lesion size compared to control mice (Ait-Oufella et al., 2006). Finally, various successful immune therapies used in atherosclerosis suggest an important role for Treg cells. Use of antiCD3 $\mathrm{mAB}$ reduced plaque formation when administered prior to a high cholesterol diet and markedly decreased lesion progression in mice with established atherosclerosis (Steffens et al., 2006). Vaccine administration into atherosclerotic prone mice of proatherogenic auto-antigens, such as apolipoprotein B-100 or heat shock protein, led to the inhibition of atherosclerosis development. Both treatments resulted in increased production of Foxp3+ Treg cells and secretion of TGF- $\beta$ and IL-10 (van Puijvelde et al., 2006; Klingenberg et al., 2010).

\section{THE PATHO-PHYSIOLOGY OF TYPE 2 DIABETES AND ITS COMPLICATIONS}

Whereas the autoimmune etiology of T1D pathogenesis is well established, T2D was historically considered a non-immune condition. However, recent work highlighting adiposity-associated chronic inflammation in T2D implicates immune mediators in metabolic dysregulation. In conjunction with adipocytes, the innate and adaptive immune system drives systemic inflammation, promoting both insulin resistance and associated complications such as diabetic nephropathy (DN). As crucial mediators of peripheral tolerance, it is not surprising that within this environment Treg cells are key regulators of adipose tissue inflammation and resultant diabetogenesis.

Excess adiposity is associated with an increase in serum Creactive protein (CRP) and pro-inflammatory cytokines such as IL-6 in humans (Visser et al., 1999). Furthermore, insulin resistance positively correlated with the levels of these cytokines in the blood of T2D patients (Bruun et al., 2003). The mechanism by which inflammatory mediators can disrupt intracellular metabolic signaling has been elucidated in mouse models. Stimulation of the JNK and NF- $\kappa \mathrm{B}$ pathways by pro-inflammatory cytokines activates negative regulators of the insulin receptor pathway. Specifically JNK and IKK- $\beta$ phosphorylate insulin receptor substrate 1 (IRS1) inhibiting tyrosine phosphorylation by the insulin receptor (Arkan et al., 2005; Sabio et al., 2010). Genetic ablation of these kinases results in significant amelioration of insulin resistance. Thus cross talk between insulin receptor and inflammatory signaling cascades can disrupt cell metabolism and exacerbate insulin resistance.

In addition to the predominant adipocyte population, lean adipose tissue contains an appreciable number of leukocytes in the absence of inflammation, suggesting involvement in fat tissue homeostasis (Lumeng et al., 2007; Feuerer et al., 2009). However, profound accumulation of inflammatory immune infiltrates accompanies the accrual of lipids in the visceral adipose tissue (mVAT) of obese mice (Weisberg et al., 2003; Nishimura et al., 2009). Most notably, macrophages of the inflammatory M1 subtype predominate in obese VAT over tolerogenic M2 macrophages found in lean fat (Lumeng et al., 2007). The M1 phenotype is the major source of pro-inflammatory cytokines that promote insulin resistance in adipocytes. Though in humans a dichotomous M1/M2 paradigm is absent, macrophages nonetheless accumulate in obese fat and drive inflammation (Zeyda et al., 2007). Recently, CD8 ${ }^{+}$Teff cells have been identified as key regulators of macrophage recruitment and switch to the M1 type in obese adipose tissue (Nishimura et al., 2009). CD8 ${ }^{+}$cells were observed prior to macrophage populations in VAT of mice when obesity was induced via high fat diet (HFD). Furthermore, in CD8 depleted or deficient mice on HFD, VAT macrophage infiltration and phenotypic switch was repressed and indices of metabolic dysfunction significantly ameliorated. Others have proposed that $\mathrm{CD}^{+} \mathrm{T}_{\mathrm{h}} 1$ cells coordinate adipose tissue inflammation, describing restored insulin sensitivity via $T_{h} 1$ cell depletion in a HFD mouse model of 
obesity (Winer et al., 2009). Collectively, these studies posit that $\mathrm{T}$ lymphocytes drive adipose tissue macrophage (ATM) recruitment and differentiation and consequent chronic inflammation in T2D.

In contrast, $\mathrm{T}$ lymphocytes can also exact essential regulatory function in adipose tissue. In both mouse and human, Foxp $3^{+}$ Treg cells have been found in both VAT and subcutaneous fat (SAT) (Feuerer et al., 2009; Eller et al., 2011; Zeyda et al., 2011). Indeed Treg cells comprised more than half of the total CD4 compartment in VAT of healthy C57BL/6 mice (Feuerer et al., 2009). These Treg cells produce high quantities of the anti-inflammatory cytokine IL-10 and uniquely express nuclear receptor PPAR- $\gamma$, which is necessary for their homeostasis and regulatory function in VAT (Feuerer et al., 2009; Cipolletta et al., 2012). Gene expression profiling indicates PPAR- $\gamma$ and Foxp3 may coordinately regulate VAT Treg transcriptional programs necessary to suppress adipose-associated inflammation. This could be akin to how recently identified Treg subsets are phenotypically specified to suppress $T_{h} 1, T_{h} 2$, or $T_{h} 17$ responses (Campbell and Koch, 2011). While in both genetic and diet-induced mouse models a waning of VAT Treg cells accompanies increasing adiposity, the effect of obesity on VAT Treg cell numbers in humans remains controversial (Feuerer et al., 2009). Whereas some groups have found FOXP3 expression to negatively correlate with BMI, others report no change or an increase in FOXP3 in the fat of obese individuals compared to normal BMI controls (Feuerer et al., 2009; Eller et al., 2011; Zeyda et al., 2011). However, these studies indirectly enumerate Treg cells via qPCR rather than flow cytometry and thus do not discriminate between FOXP3 expression by bona fide Treg cells, and transient FOXP3 upregulation by Teff cells upon activation. Nevertheless, such findings highlight the risk in literal application of established mouse models to human T2D.

Thus $\mathrm{T}$ cells direct adipose-induced systemic inflammation and therefore may indirectly promote $\mathrm{T} 2 \mathrm{D}$ complications via metabolic disruption. Further evidence suggests T cells could mediate immunopathology directly in the target organ. For instance, profound infiltration of the kidneys by activated $\mathrm{T}$ cells is associated with the development of DN in T2D patients (Moon et al., 2012). This is accompanied by macrophage accumulation and production of pro-inflammatory cytokines such as IFN- $\gamma$ and IL- $1 \beta$ (Galkina and Ley, 2006). However the relative contribution of inflammatory verses metabolic and hemodynamic factors to the initiation and progression of renal lesions remains unclear. A study of $\mathrm{DN}$ in $\mathrm{db} / \mathrm{db}$ mice suggests Treg cells may dampen kidney immunopathology (Eller et al., 2011). Treg depletion via administration of anti-CD25 antibodies exacerbated nephropathy, renal dysfunction and leukocyte infiltration of the kidneys. Furthermore, adoptive transfer of Treg cells into $\mathrm{db} / \mathrm{db}$ mice improved kidney function and ameliorated DN. Thus, Treg cells suppress inflammation both at the primary and secondary sites of T2D pathogenesis. Like in T1D, Treg cells may represent a key homeostatic checkpoint that, if breached, results in the breakdown of peripheral tolerance and progression of autoreactive responses.

\section{IMMUNOTHERAPEUTIC STRATEGIES: CURRENT AND FUTURE AVENUES}

Type 1 diabetes susceptibility and pathogenesis results from a complex interplay between genetic, environmental, and immunological factors. Therefore, a multi-faceted solution is likely necessary to effectively treat T1D. An ideal immunotherapy would simultaneously shut down pathogenic $\mathrm{T}$ cells and enhance regulatory mechanisms, while also promoting $\beta$-cell regeneration or neogenesis. All three therapeutic goals have been proposed to occur through anti-CD3 mAB therapy. Anti-CD3 works as an immune suppressant, promotes antigen-specific Treg cells and both increases and preserves $\beta$-cell mass. Anti-CD3 mAB causes internalization of the CD3-TCR complex and prevents Teff cells from recognizing antigen. Furthermore it affects TCR-mediated signal transduction and provokes apoptosis and anergy of Teff cells (Chatenoud et al., 1982, 1994). Beyond modulation of effectors cell pools, anti-CD3 has recently been shown to promote induction and stabilization of Treg cells (You et al., 2007; Penaranda et al., 2011). Two independent clinical trials using either Teplizumab (United States) or Otelixizumab (Europe) led to the sustained preservation of insulin production. In NOD mice, anti-CD3 therapy permanently reversed diabetes and in humans $\mathrm{C}$-peptide levels were sustained from 1 to 5 years, demonstrating long term protection could be obtained (Herold et al., 2002, 2009; Keymeulen et al., 2005).

Can antigen-specific therapies prevent the immune-driven pathology in disease? In T1D, several studies had focused on the use of insulin and GAD65 as a primary targets for antigen-specific therapies as they are proposed to be key initiating auto-antigens in NOD mice and major auto-antigens in human. The most prominent clinical trial so far involves oral insulin administration in first-degree relatives of T1D patients with high levels of insulin autoantibodies. This regimen modulates diabetogenic immune responses and consequently delays diabetes onset by as much as 5 years (Skyler et al., 2005). In addition, a single injection of the GAD-alum vaccine, the most successful antigen-specific therapy to date, delayed the loss of C-peptide production in new onset T1D children and adolescents (Ludvigsson et al., 2008). Administration of agents such as gastrin that stimulate beta cell neogenesis without increasing proliferation, can minimize antigen spread and prevent $\beta$-cell loss (Rooman et al., 2002). Lastly, modulation of local tissue or systemic metabolism, possibly by targeting the PPAR- $\gamma$ pathway, may impact the generation of adipose-related Treg cells and suppress local inflammatory responses.

\section{CONCLUSION}

Thus in T1D and T2D, inflammation in the target tissue and at secondary sites drives disease progression. Whereas in T1D this response is quintessentially autoimmune, the factors that initiate adipose tissue inflammation in T2D have yet to be elucidated. However, in both conditions innate and adaptive leukocyte infiltration and local tissue destruction instigate chronic systemic inflammation. This promotes diabetogenic complications including autoimmune responses at secondary tissues and metabolic perturbation in T2D. Treg cells, potent suppressors of autoimmunity in the periphery, can dampen immune effector cell responses in the $\beta$-islets. Furthermore, an important role for this subset in inflamed adipose tissue has recently been characterized. Thus, enhancing the activity of Treg cells may present a therapeutic avenue to limit type 1 and type 2 diabetes pathogenesis and its complications. 


\section{ACKNOWLEDGMENTS}

We acknowledge grant support from the Canadian Institutes for Health Research (CIHR) [MOP 67211] (Ciriaco A. Piccirillo), and from the Canada Research Chair (Ciriaco A. Piccirillo) program. Mara Kornete is a recipient of doctoral fellowship from FRSQ.

\section{REFERENCES}

Abdul-Rasoul, M., Habib, H., and Al-Khouly, M. (2006). The honeymoon phase' in children with type 1 diabetes mellitus: frequency, duration, and influential factors. Pediatr. Diabetes 7, 101-107. doi:10.1111/j.1399543X.2006.00155.x

Ablamunits, V., Sherry, N. A., Kushner, J. A., and Herold, K. C. (2007). Autoimmunity and beta cell regeneration in mouse and human type 1 diabetes: the peace is not enough. Ann. N. Y. Acad. Sci. 1103, 19-32. doi:10.1196/annals.1394.006

Ait-Oufella, H., Salomon, B. L., Potteaux, S., Robertson, A. K., Gourdy, P., Zoll, J., et al. (2006). Natural regulatory $\mathrm{T}$ cells control the development of atherosclerosis in mice. Nat. Med. 12, 178-180. doi:10.1038/nm1343

Akirav, E., Kushner, J. A., and Herold, K. C. (2008). Beta-cell mass and type 1 diabetes: going, going, gone? Diabetes 57, 2883-2888. doi:10.2337/db07-1817

Anderson, M. S., and Bluestone, J. A. (2005). The NOD mouse: a model of immune dysregulation. Annu. Rev. Immunol. 23, 447-485. doi:10. 1146/annurev.immunol.23.021704. 115643

Arkan, M. C., Hevener, A. L., Greten, F. R., Maeda, A., Li, Z. W., Long, J. M., et al. (2005). IKK-beta links inflammation to obesity-induced insulin resistance. Nat. Med. 11, 191-198. doi:10.1038/nm1185

Atkinson, M. A., and Leiter, E. H. (1999). The NOD mouse model of type 1 diabetes: as good as it gets? Nat. Med. 5, 601-604. doi:10.1038/9442

Bach, J. F., and Chatenoud, L. (2001). Tolerance to islet autoantigens in type 1 diabetes. Annu. Rev. Immunol. 19, 131-161. doi:10.1146/ annurev.immunol.19.1.131

Berg, A. K., Korsgren, O., and Frisk, G. (2006). Induction of the chemokine interferon-gamma-inducible protein-10 in human pancreatic islets during enterovirus infection. Diabetologia 49, 2697-2703. doi:10.1007/s00125-006-0429-7

Bruun, J. M., Verdich, C., Toubro, S., Astrup, A., and Richelsen, B. (2003). Association between measures of insulin sensitivity and circulating levels of interleukin-8, interleukin6 and tumor necrosis factor-alpha. Effect of weight loss in obese men.
Eur. J. Endocrinol. 148, 535-542. doi:10.1530/eje.0.1480535

Campbell, D. J., and Koch, M. A. (2011). Phenotypical and functional specialization of FOXP3+ regulatory $\mathrm{T}$ cells. Nat. Rev. Immunol. 11, 119-130. doi:10.1038/nri2916

Chatenoud, L., Baudrihaye, M. F., Kreis, H., Goldstein, G., Schindler, J., and Bach, J. F. (1982). Human in vivo antigenic modulation induced by the anti-T cell OKT3 monoclonal antibody. Eur. J. Immunol. 12, 979-982. doi:10.1002/eji.1830121116

Chatenoud, L., Thervet, E., Primo, J., and Bach, J. F. (1994). AntiCD3 antibody induces long-term remission of overt autoimmunity in nonobese diabetic mice. Proc. Natl. Acad. Sci. U.S.A. 91, 123-127. doi:10.1073/pnas.91.1.123

Chervonsky, A. V. (2010). Influence of microbial environment on autoimmunity. Nat. Immunol. 11, 28-35. doi:10.1038/ni.1801

Christen, U., Mcgavern, D. B., Luster, A. D., Von Herrath, M. G., and Oldstone, M. B. A. (2003). Among CXCR3 chemokines, IFN-1 $\hat{1}^{3}$ inducible protein of $10 \mathrm{kDa}$ (CXC chemokine ligand (CXCL) 10) but not monokine induced by IFN- $\hat{1}^{3}$ (CXCL9) imprints a pattern for the subsequent development of autoimmune disease. J. Immunol. 171, 6838-6845.

Chung, C. H., Hao, E., Piran, R., Keinan, E., and Levine, F. (2010). Pancreatic beta-cell neogenesis by direct conversion from mature alphacells. Stem Cells 28, 1630-1638. doi:10.1002/stem.482

Cipolletta, D., Feuerer, M., Li, A., Kamei, N., Lee, J., Shoelson, S. E., et al. (2012). PPAR-gamma is a major driver of the accumulation and phenotype of adipose tissue Treg cells. Nature 486, 549-553. doi:10.1038/nature 11132

de Boer, O. J., Van Der Meer, J. J., Teeling, P., Van Der Loos, C. M., and Van Der Wal, A. C. (2007). Low numbers of FOXP3 positive regulatory $\mathrm{T}$ cells are present in all developmental stages of human atherosclerotic lesions. PLoS ONE 2:e779. doi:10.1371/journal.pone.0000779

d'Hennezel, E., Bin Dhuban, K., Torgerson, T., and Piccirillo, C. A. (2012). The immunogenetics of immune dysregulation, polyendocrinopathy, enteropathy, X linked
(IPEX) syndrome. J. Med. Genet. 49, 291-302. doi:10.1136/jmedgenet2012-100759

Donath, M. Y., Storling, J., Maedler, K. and Mandrup-Poulsen, T. (2003). Inflammatory mediators and islet beta-cell failure: a link between type 1 and type 2 diabetes. $J$. Mol. Med. (Berl.) 81, 455-470. doi:10.1007/s00109-003-0450-y

Dor, Y., Brown, J., Martinez, O. I., and Melton, D. A. (2004). Adult pancreatic beta-cells are formed by self-duplication rather than stem-cell differentiation. Nature 429, 41-46. doi:10.1038/ nature 02520

Eller, K., Kirsch, A., Wolf, A. M., Sopper, S., Tagwerker, A., Stanzl, U., et al. (2011). Potential role of regulatory $\mathrm{T}$ cells in reversing obesity-linked insulin resistance and diabetic nephropathy. Diabetes 60, 2954-2962. doi:10.2337/ db11-0358

Fernandes, A., King, L. C., Guz, Y., Stein, R., Wright, C. V., and Teitelman, G. (1997). Differentiation of new insulin-producing cells is induced by injury in adult pancreatic islets. Endocrinology 138, 1750-1762. doi:10.1210/en.138.4.1750

Feuerer, M., Herrero, L., Cipolletta D., Naaz, A., Wong, J., Nayer A., et al. (2009). Lean, but not obese, fat is enriched for a unique population of regulatory $\mathrm{T}$ cells that affect metabolic parameters. Nat. Med. 15, 930-939. doi:10.1038/ nm.2002

Fontenot, J. D., Rasmussen, J. P. Gavin, M. A., and Rudensky, A. Y. (2005). A function for interleukin 2 in Foxp3-expressing regulatory $\mathrm{T}$ cells. Nat. Immunol. 6, 1142-1151. doi:10.1038/ni1263

Galkina, E., and Ley, K. (2006). Leukocyte recruitment and vascular injury in diabetic nephropathy. J. Am. Soc. Nephrol. 17, 368-377. doi:10.1681/ASN.2005080859

Grinberg-Bleyer, Y., Baeyens, A., You, S., Elhage, R., Fourcade, G., Gregoire, S., et al. (2010). IL-2 reverses established type 1 diabetes in NOD mice by a local effect on pancreatic regulatory $\mathrm{T}$ cells. J. Exp. Med. 207, 1871-1878. doi:10.1084/jem.20100209

Guz, Y., Nasir, I., and Teitelman, G. (2001). Regeneration of pancreatic beta cells from intra-islet precursor cells in an experimental model of diabetes. Endocrinology 142, 4956-4968. doi:10.1210/en.142.11.4956

Haiqi, H., Yong, Z., and Yi, L. (2011). Transcriptional regulation of Foxp3 in regulatory $\mathrm{T}$ cells. Immunobiology 216, 678-685. doi:10.1016/j.imbio.2010.11.002

Herold, K. C., Gitelman, S., Greenbaum, C., Puck, J., Hagopian, W., Gottlieb, P., et al. (2009). Treatment of patients with new onset Type 1 diabetes with a single course of anti-CD3 mAb Teplizumab preserves insulin production for up to 5 years. Clin. Immunol. 132, 166-173. doi:10.1016/j.clim.2009. 04.007

Herold, K. C., Hagopian, W., Auger, J. A., Poumian-Ruiz, E., Taylor, L., Donaldson, D., et al. (2002). Anti-CD3 monoclonal antibody in new-onset type 1 diabetes mellitus. N. Engl. J. Med. 346, 1692-1698. doi:10.1056/NEJMoa012864

Hori, S., Nomura, T., and Sakaguchi, S. (2003). Control of regulatory $\mathrm{T}$ cell development by the transcription factor Foxp3. Science 299, 1057-1061. doi:10.1126/science. 1079490

Kaufman, D. L., Erlander, M. G., Clare-Salzler, M., Atkinson, M. A., Maclaren, N. K., and Tobin, A. J. (1992). Autoimmunity to two forms of glutamate decarboxylase in insulin-dependent diabetes mellitus. J. Clin. Invest. 89, 283-292. doi:10.1172/JCI115573

Keymeulen, B., Vandemeulebroucke, E., Ziegler, A. G., Mathieu, C., Kaufman L., Hale, G., et al. (2005). Insulin needs after CD3-antibody therapy in new-onset type 1 diabetes. N. Engl. J. Med. 352, 2598-2608. doi:10.1056/NEJMoa043980

Klingenberg, R., Lebens, M., Hermansson, A., Fredrikson, G. N. Strodthoff, D., Rudling, M., et al. (2010). Intranasal immunization with an apolipoprotein B100 fusion protein induces antigenspecific regulatory $\mathrm{T}$ cells and reduces atherosclerosis. Arterioscler. Thromb. Vasc. Biol. 30, 946-952. doi:10.1161/ATVBAHA.109.202671

Knip, M., Veijola, R., Virtanen, S. M., Hyoty, H., Vaarala, O., and Akerblom, H. K. (2005). Environmental triggers and determinants of type 1 diabetes. Diabetes 54(Suppl. 2), S125-S136. doi:10. 2337/diabetes.54.suppl_2.S125 
Kornete, M., Sgouroudis, E., and Piccirillo, C. A. (2012). ICOSdependent homeostasis and function of Foxp3+ regulatory $\mathrm{T}$ cells in islets of nonobese diabetic mice. J. Immunol. 188, 1064-1074. doi:10.4049/jimmunol.1101303

Krishnamurthy, B., Dudek, N. L., Mckenzie, M. D., Purcell, A. W., Brooks, A. G., Gellert, S., et al. (2006). Responses against islet antigens in NOD mice are prevented by tolerance to proinsulin but not IGRP. J. Clin. Invest. 116, 3258-3265. doi:10.1172/ JCI29602

Long, S. A., Cerosaletti, K., Bollyky, P. L., Tatum, M., Shilling, H., Zhang, S., et al. (2010). Defects in IL-2R signaling contribute to diminished maintenance of FOXP3 expression in $\mathrm{CD} 4(+) \mathrm{CD} 25(+)$ regulatory T-cells of type 1 diabetic subjects. Diabetes 59, 407-415. doi:10.2337/db09-0694

Ludvigsson, J., Faresjo, M., Hjorth, M., Axelsson, S., Cheramy, M., Pihl, M., et al. (2008). GAD treatment and insulin secretion in recent-onset type 1 diabetes. N. Engl. J. Med. 359, 1909-1920. doi:10.1056/NEJMoa0804328

Lumeng, C. N., Bodzin, J. L., and Saltiel, A. R. (2007). Obesity induces a phenotypic switch in adipose tissue macrophage polarization. J. Clin. Invest. 117, 175-184. doi:10.1172/JCI29881

Luo, X., Yang, H., Kim, I. S., SaintHilaire, F., Thomas, D. A., De, B. P., et al. (2005). Systemic transforming growth factor-betal gene therapy induces Foxp3+ regulatory cells, restores self-tolerance, and facilitates regeneration of beta cell function in overtly diabetic nonobese diabetic mice. Transplantation 79, 1091-1096. doi:10. 1097/01.TP.0000161223.54452.A2

Lyons, P. A., Armitage, N., Argentina, F., Denny, P., Hill, N. J., Lord, C. J., et al. (2000). Congenic mapping of the type 1 diabetes locus, Idd3, to a $780-\mathrm{kb}$ region of mouse chromosome 3: identification of a candidate segment of ancestral DNA by haplotype mapping. Genome Res. 10, 446-453. doi:10.1101/ gr.10.4.446

Mallat, Z., Gojova, A., Brun, V., Esposito, B., Fournier, N., Cottrez, F., et al. (2003). Induction of a regulatory $\mathrm{T}$ cell type 1 response reduces the development of atherosclerosis in apolipoprotein E-knockout mice. Circulation 108, 1232-1237. doi:10. 1161/01.CIR.0000089083.61317.A1

Mathis, D., and Benoist, C. (2012). The influence of the microbiota on type-1 diabetes: on the threshold of a leap forward in our understanding. Immunol. Rev. 245, 239-249. doi:10.1111/j.1600065X.2011.01084.X

McClymont, S. A., Putnam, A. L., Lee, M. R., Esensten, J. H., Liu, W., Hulme, M. A., et al. (2011). Plasticity of human regulatory $\mathrm{T}$ cells in healthy subjects and patients with type 1 diabetes. J. Immunol. 186, 3918-3926. doi:10.4049/jimmunol.1003099

Moon, J. Y., Jeong, K. H., Lee, T. W., Ihm, C. G., Lim, S. J., and Lee, S. H. (2012). Aberrant recruitment and activation of $\mathrm{T}$ cells in diabetic nephropathy. Am. J. Nephrol. 35, 164-174. doi:10.1159/ 000334928

Muhammad, B. J., Swift, P. G. F., Raymond, N. T., and Botha, J. L. (1999). Partial remission phase of diabetes in children younger than age 10 years. Arch. Dis. Child. 80, 367-369. doi:10.1136/adc.80.4.367

Nir, T., Melton, D. A., and Dor, Y. (2007). Recovery from diabetes in mice by beta cell regeneration. J. Clin. Invest. 117, 2553-2561. doi:10.1172/JCI32959

Nishimura, S., Manabe, I., Nagasaki, M., Eto, K., Yamashita, H., Ohsugi, M., et al. (2009). CD8+ effector T cells contribute to macrophage recruitment and adipose tissue inflammation in obesity. Nat. Med. 15, 914-920. doi:10.1038/nm.1964

Orban, T., Sosenko, J. M., Cuthbertson, D., Krischer, J. P., Skyler, J. S., Jackson, R., et al. (2009). Pancreatic islet autoantibodies as predictors of type 1 diabetes in the Diabetes Prevention Trial-Type 1. Diabetes Care 32, 2269-2274. doi:10.2337/ dc09-0934

Penaranda, C., Tang, Q., and Bluestone, J. A. (2011). Anti-CD3 therapy promotes tolerance by selectively depleting pathogenic cells while preserving regulatory $\mathrm{T}$ cells. J. Immunol. 187, 2015-2022. doi:10.4049/jimmunol.1100713

Piccirillo, C. A., Tritt, M., Sgouroudis, E., Albanese, A., Pyzik, M., and Hay, V. (2005). Control of type 1 autoimmune diabetes by naturally occurring $\mathrm{CD} 4+\mathrm{CD} 25+$ regulatory $\mathrm{T}$ lymphocytes in neonatal NOD mice. Ann. N. Y. Acad. Sci. 1051, 72-87. doi:10.1196/annals.1361.048

Rooman, I., Lardon, J., and Bouwens, L. (2002). Gastrin stimulates betacell neogenesis and increases islet mass from transdifferentiated but not from normal exocrine pancreas tissue. Diabetes 51, 686-690. doi:10.2337/diabetes.51.3.686
Sabbah, E., Savola, K., Kulmala, P., Veijola, R., Vahasalo, P., Karjalainen, J., et al. (1999). Diabetes-associated autoantibodies in relation to clinical characteristics and natural course in children with newly diagnosed type 1 diabetes. The Childhood Diabetes in Finland Study Group. J. Clin. Endocrinol. Metab. 84, 1534-1539. doi:10.1210/ jc.84.5.1534

Sabio, G., Kennedy, N. J., CavanaghKyros, J., Jung, D. Y., Ko, H. J., Ong, H., et al. (2010). Role of muscle c-Jun NH2-terminal kinase 1 in obesity-induced insulin resistance. Mol. Cell. Biol. 30, 106-115. doi:10.1128/MCB.01162-09

Sakaguchi, S., Wing, K., Onishi, Y., Prieto-Martin, P., and Yamaguchi, T. (2009). Regulatory T cells: how do they suppress immune responses? Int. Immunol. 21, 1105-1111. doi:10.1093/intimm/dxp095

Salomon, B., and Bluestone, J. A. (2001). Complexities of CD28/B7: CTLA-4 costimulatory pathways in autoimmunity and transplantation. Annu. Rev. Immunol. 19, 225-252. doi:10. 1146/annurev.immunol.19.1.225

Salomon, B. T., Lenschow, D. J., Rhee, L., Ashourian, N., Singh, B., Sharpe, A. et al. (2000). B7/CD28 costimulation is essential for the homeostasis of the CD4+CD25+ immunoregulatory $\mathrm{T}$ cells that control autoimmune diabetes. Immunity 12, 431-440. doi:10. 1016/S1074-7613(00)80195-8

Sgouroudis, E., Albanese, A., and Piccirillo, C. A. (2008). Impact of protective IL-2 allelic variants on CD4+ Foxp3+ regulatory $\mathrm{T}$ cell function in situ and resistance to autoimmune diabetes in NOD mice. J. Immunol. 181, 6283-6292.

Shen, Z., Chen, L., Hao, F., and Wu, J. (2009). Transcriptional regulation of Foxp3 gene: multiple signal pathways on the road. Med. Res. Rev. 29, 742-766. doi:10.1002/ med. 20152

Sherry, N. A., Kushner, J. A., Glandt, M., Kitamura, T., Brillantes, A. M. and Herold, K. C. (2006). Effects of autoimmunity and immune therapy on beta-cell turnover in type 1 diabetes. Diabetes 55, 3238-3245. doi:10.2337/db05-1034

Shevach, E. M. (2009). Mechanisms of Foxp3+ T regulatory cell-mediated suppression. Immunity 30, 636-645. doi:10.1016/j.immuni

Skyler, J. S., Krischer, J. P., Wolfsdorf, J., Cowie, C., Palmer, J. P., Greenbaum, C., et al. (2005). Effects of oral insulin in relatives of patients with type 1 diabetes: The Diabetes Prevention Trial - Type
1. Diabetes Care 28, 1068-1076. doi:10.2337/diacare.28.5.1068

Steffens, S., Burger, F., Pelli, G., Dean, Y., Elson, G., Kosco-Vilbois, M., et al. (2006). Short-term treatment with anti-CD3 antibody reduces the development and progression of atherosclerosis in mice. Circulation 114, 1977-1984. doi:10.1161/ CIRCULATIONAHA.106.627430

Tang, Q., Adams, J. Y., Penaranda, C., Melli, K., Piaggio, E., Sgouroudis, E., et al. (2008). Central role of defective interleukin-2 production in the triggering of islet autoimmune destruction. Immunity 28, 687-697. doi:10.1016/ j.immuni.2008.03.016

Thorel, F., Nepote, V., Avril, I., Kohno, K., Desgraz, R., Chera, S., et al. (2010). Conversion of adult pancreatic alpha-cells to beta-cells after extreme beta-cell loss. Nature 464, 1149-1154. doi:10.1038/nature08894

Thyssen, S., Arany, E., and Hill, D. J. (2006). Ontogeny of regeneration of beta-cells in the neonatal rat after treatment with streptozotocin. Endocrinology 147, 2346-2356. doi:10.1210/en.2005-0396

Tritt, M., Sgouroudis, E., d'Hennezel, E., Albanese, A., and Piccirillo, C. A. (2008). Functional waning of naturally occurring CD4+ regulatory T-cells contributes to the onset of autoimmune diabetes. Diabetes 57, 113-123. doi:10.2337/db06-1700

Tuch, B. E., Simpson, A. M., and Campbell, I. L. (1991). Role of tumor necrosis factor-alpha and interferon-gamma as growth factors to the human fetal beta-cell. J. Clin. Endocrinol. Metab. 73, 1044-1050. doi:10.1210/jcem-73-5-1044

van Puijvelde, G. H., Hauer, A. D., De Vos, P., Van Den Heuvel, R., Van Herwijnen, M. J., Van Der Zee, R., et al. (2006). Induction of oral tolerance to oxidized low-density lipoprotein ameliorates atherosclerosis. Circulation 114, 1968-1976. doi:10.1161/ CIRCULATIONAHA.106.615609

Veillard, N. R., Steffens, S., Burger, F., Pelli, G., and Mach, F. (2004). Differential expression patterns of proinflammatory and antiinflammatory mediators during atherogenesis in mice. Arterioscler. Thromb. Vasc. Biol. 24, 2339-2344. doi:10.1161/ 01.ATV.0000146532.98235.e6

Visser, M., Bouter, L. M., McQuillan, G. M., Wener, M. H., and Harris, T. B. (1999). Elevated Creactive protein levels in overweight and obese adults. JAMA 282, 2131-2135. doi:10.1001/jama.282. 22.2131 
Weisberg, S. P., Mccann, D., Desai, M., Rosenbaum, M., Leibel, R. L., and Ferrante, A. W. Jr. (2003). Obesity is associated with macrophage accumulation in adipose tissue. J. Clin. Invest. 112, 1796-1808. doi:10.1172/JCI19246

Winer, S., Chan, Y., Paltser, G., Truong, D., Tsui, H., Bahrami, J., et al. (2009). Normalization of obesityassociated insulin resistance through immunotherapy. Nat. Med. 15, 921-929. doi:10.1038/nm.2001

You, S., Leforban, B., Garcia, C., Bach, J. F., Bluestone, J. A., and Chatenoud, L. (2007). Adaptive TGFbeta-dependent regulatory $\mathrm{T}$ cells control autoimmune diabetes and are a privileged target of anti-CD3 antibody treatment. Proc. Natl.
Acad. Sci. U.S.A. 104, 6335-6340. doi:10.1073/pnas.0701171104

Zaret, K. S., and White, M. F. (2010). Diabetes forum: extreme makeover of pancreatic alphacells. Nature 464, 1132-1133. doi:10.1038/4641132a

Zeyda, M., Farmer, D., Todoric, J., Aszmann, O., Speiser, M., Gyori, G., et al. (2007). Human adipose tissue macrophages are of an antiinflammatory phenotype but capable of excessive pro-inflammatory mediator production. Int. J. Obes. (Lond.) 31, 1420-1428. doi:10.1038/ sj.ijo. 0803632

Zeyda, M., Huber, J., Prager, G., and Stulnig, T. M. (2011). Inflammation correlates with markers of T-cell subsets including regulatory $\mathrm{T}$ cells in adipose tissue from obese patients. Obesity (Silver Spring) 19, 743-748. doi:10.1038/oby.2010.123

Zhou, X., Bailey-Bucktrout, S. L. Jeker, L. T., Penaranda, C., Martinez-Llordella, M., Ashby, M., et al. (2009). Instability of the transcription factor Foxp3 leads to the generation of pathogenic memory $\mathrm{T}$ cells in vivo. Nat. Immunol. 10, 1000-1007. doi:10.1038/ni.1774

Conflict of Interest Statement: The authors declare that the research was conducted in the absence of any commercial or financial relationships that could be construed as a potential conflict of interest.
Received: 02 May 2013; accepted: 08 June 2013; published online: 25 June 2013.

Citation: Kornete M, Mason ES and Piccirillo CA (2013) Immune regulation in T1D and T2D: prospective role of Foxp3+ Treg cells in disease pathogenesis and treatment. Front. Endocrinol. 4:76. doi: 10.3389/fendo.2013.00076

This article was submitted to Frontier in Diabetes, a specialty of Frontiers in Endocrinology.

Copyright (־ 2013 Kornete, Mason and Piccirillo. This is an open-access article distributed under the terms of the Creative Commons Attribution License, which permits use, distribution and reproduction in other forums, provided the original authors and source are credited and subject to any copyright notices concerning any third-party graphics etc. 